\title{
Alteromonas atlantica sp. nov. and Alteromonas carrageenovora sp. nov., Bacteria That Decompose Algal Polysaccharides

\author{
MASAYO AKAGAWA-MATSUSHITA, ${ }^{1 *}$ MASARU MATSUO, ${ }^{2}$ YOSUKE KOGA, ${ }^{1}$ \\ AND KAZUHIDE YAMASATO ${ }^{3}$
} \\ Department of Chemistry, University of Occupational and Environmental Health, Yahatanishi-ku, Kitakyushu $807,{ }^{1}$ Institute of Applied Biochemistry, The University of Tsukuba, Tsukuba-shi, Ibaraki $305,{ }^{2}$ and Institute of Applied Microbiology, The University of Tokyo, Bunkyo-ku, Tokyo 113, ${ }^{3}$ Japan
}

\begin{abstract}
We studied seven strains of aerobic, marine, polarly flagellated bacteria which decompose alginate, agar, and carrageenan. The major respiratory quinone of these strains was ubiquinone-8. The $G+C$ content of their DNA was 39.5 to 41.7 mol\%. "Pseudomonas atlantica" IAM 12927 and the conspecific five isolates were concluded to constitute a single species distinguished from the other nonpigmented Alteromonas species by DNA-DNA hybridization (homology values of more than $82 \%$ ) and phenotypic similarity (similarity coefficients, based on assimilation of 145 carbon compounds, were 79 to 96\%). "Pseudomonas carrageenovora" IAM 12662, the sole extant strain, was distinct from "P. atlantica" and other Alteromonas species in DNA-DNA hybridization and phenotypic features. Taxonomic affinity to Alteromonas espejiana was indicated by DNA-DNA hybridization with “ $P$. atlantica" IAM 12927 and the five conspecific isolates (39 to $55 \%$ ) and with "P. carrageenovora" IAM 12662 (43 to 45\%). Phenotypically, higher similarity values (79 to $89 \%)$ for assimilation of 145 carbon compounds were shared between $A$. espejiana IAM $12927^{\mathrm{T}}$ and the six conspecific strains, including “P. atlantica” IAM 12927. Alteromonas atlantica sp. nov. (type strain, IAM 12927, =ATCC 19262, =NCIMB 301) and Alteromonas carrageenovora (type strain, IAM 12662, = IFO 12985, =ATCC 43555, $=$ NCIMB 302) are proposed for " $P$. atlantica" IAM 12927 and the conspecific five isolates and " $P$. carrageenovora" LAM 12662, respectively. A set of phenotypic features which differentiate the two Alteromonas species is described.
\end{abstract}

Marine algal polysaccharides are potent resources for biomass, and their microbial degradation is primarily necessary for the development of their practical use. The enzymes that degrade polysaccharides of diversified structures are of interest from an enzymological standpoint. Biomacromolecule-degrading microorganisms were found in Vibrio-related bacteria $(4,6,7,10)$, yellow Cytophaga-like bacteria $(16,21$, 30), aerobic Pseudomonas-like bacteria $(5,13,17,23,26-$ 28 , and some actinomycetes (10). The genus Alteromonas was created in 1972 for marine bacteria that are Pseudomonas like but which have a lower $\mathrm{G}+\mathrm{C}$ content (8). rRNADNA hybridization experiments showed that the genus Alteromonas comprises two phylogenetic descents (22). Some marine strains, formerly identified as Pseudomonas species, belonged in the Alteromonas haloplanktis rRNA branch $(9,22)$.

"Pseudomonas atlantica" IAM 12927, which was originally isolated by W. Yaphe (27), is an agar-decomposing strain, and its agarase is widely used and commercially available. "Pseudomonas carrageenovora" IAM 12662 is a carrageenan-decomposing strain, and several enzymological studies of its carrageenases have been reported $(12,14,24$, $25,28,29)$. The names of these two strains have not been validated, and their generic assignment has been thought to be incorrect. They belong in the genus Alteromonas, according to rRNA-DNA hybridization by De Vos et al. (9). However, their assignment at a species-specific level has remained unclarified. $M$. Matsuo isolated several strains of gram-negative, polarly flagellated rods which decomposed carrageenan from seaweed collected in Japan. In this study, DNA-DNA hybridization and phenotypic characterization, including carbon source assimilation tests and chemotaxo-

\footnotetext{
* Corresponding author.
}

nomic analyses, were performed to clarify the taxonomic assignment of five unnamed strains, " $P$. atlantica" IAM 12927 , and " $P$. carrageenovora" IAM 12662, all of which decompose agar and/or carrageenan.

\section{MATERIALS AND METHODS}

Bacterial strains. The strains used in this study are listed in Table 1. Five strains of Alteromonas atlantica were isolated from seaweeds collected at Inubousaki, Choshi-city, Chiba Prefecture, Japan. To enrich carrageenan-decomposing bacteria, aliquots of $10 \mathrm{ml}$ of seawater containing $200 \mathrm{mg}$ of a powdered brown alga (Lessonia species) were inoculated with pieces of seaweed and incubated with reciprocal shaking (160 times per minute) at $25^{\circ} \mathrm{C}$ for 66 to $70 \mathrm{~h}$. The decomposition of carrageenan in culture broth was checked by estimating the amount of reducing sugar produced and monitoring the decrease of viscosity of the culture fluid. The carrageenan-decomposing strains were isolated from the enriched cultures by plating on agar plates. The medium was composed of $2.5 \mathrm{~g}$ of Casamino Acids (catalog no. 1230; Difco), $2.5 \mathrm{~g}$ of carrageenan, $50 \mathrm{ml}$ of $0.2 \mathrm{M}$ sodium phosphate buffer ( $\mathrm{pH} 8.0$ ), $500 \mathrm{ml}$ of seawater, $450 \mathrm{ml}$ of distilled water, and $15 \mathrm{~g}$ of agar; its $\mathrm{pH}$ was adjusted to 7.0 before autoclaving. Colonies were picked up after 3 days of incubation at $25^{\circ} \mathrm{C}$. $A$. atlantica IAM 12927 was received as "Pseudomonas atlantica" NCMB 301 (NCIMB 301 at present), which was originally isolated by W. Yaphe in 1957 (27) as an agar-decomposing pseudomonad. A. carrageenovora IAM 12662 was received as " $P$. carrageenovora" IFO 12985. Type strains of nonpigmented Alteromonas species, including $A$. macleodii IAM $12920^{\mathrm{T}}$, $A$. espejiana IAM $12640^{\mathrm{T}}$, A. haloplanktis IAM $12915^{\mathrm{T}}$, A. undina IAM $12922^{\mathrm{T}}$, $A$. nigrifaciens IAM $13010^{\mathrm{T}}$, and $A$. tetraodonis IAM $14160^{\mathrm{T}}$, were used as reference strains (superscript $\mathrm{T}$ de- 
TABLE 1. DNA-DNA homology among Alteromonas strains

\begin{tabular}{|c|c|c|c|c|c|}
\hline \multirow[b]{2}{*}{ Strain } & \multirow{2}{*}{$\begin{array}{l}\mathrm{G}+\mathrm{C} \text { content } \\
(\mathrm{mol} \%)\end{array}$} & \multicolumn{4}{|c|}{$\%$ Association with ${ }^{3} \mathrm{H}$-labeled DNA from: } \\
\hline & & $\begin{array}{l}\text { A. atlanticd } \\
\text { IAM } 12927^{\mathrm{T}}\end{array}$ & $\begin{array}{l}\text { A. espejiana } \\
\text { IAM } 12640^{\mathrm{T}}\end{array}$ & $\begin{array}{l}\text { A. carrageenovora } \\
\text { IAM } 12622^{\mathrm{T}}\end{array}$ & $\begin{array}{l}\text { A. tetraodonis } \\
\text { IAM } 14160^{\mathrm{T}}\end{array}$ \\
\hline A. atlantica IAM $12927^{\mathrm{Ta}}$ & 41.2 & 100 & 40 & 26 & 23 \\
\hline A. atlantica $512-\mathrm{M}$ & 40.8 & 95 & 39 & & \\
\hline A. atlantica $512-\mathrm{T}$ & 41.0 & 95 & 41 & & \\
\hline A. atlantica $512-\mathrm{W}$ & 40.6 & 100 & 55 & & \\
\hline A. atlantica $511-\mathrm{T}$ & 41.7 & 82 & 47 & & \\
\hline A. atlantica $\mathrm{T} 9$ & 40.7 & 82 & 53 & & \\
\hline A. espejiana IAM $12640^{\mathrm{T}}$ & 41.4 & 43 & 100 & 45 & 22 \\
\hline A. carrageenovora IAM $12662^{\mathrm{Tb}}$ & 39.5 & 21 & 43 & 100 & 26 \\
\hline A. haloplanktis IAM $12915^{\mathrm{T}}$ & 41.6 & 27 & 23 & 21 & \\
\hline A. undina IAM $12922^{\mathrm{T}}$ & 40.1 & 25 & 25 & 21 & \\
\hline A. nigrifaciens IAM $13010^{\mathrm{T}}$ & 40.6 & 32 & 21 & 23 & \\
\hline A. tetraodonis IAM $14160^{\mathrm{T}}$ & 40.8 & & & & 100 \\
\hline A. macleodii IAM $12920^{\mathrm{T}}$ & 46.2 & 6 & 7 & 4 & \\
\hline M. communis IAM $12914^{\mathrm{T}}$ & 47.0 & 4 & 5 & 4 & \\
\hline M. vaga IAM $12923^{\mathrm{T}}$ & 48.4 & 4 & 4 & 4 & \\
\hline E. coli IAM $1264^{c}$ & 51.3 & 4 & 3 & 3 & 4 \\
\hline
\end{tabular}

$a=$ NCIMB 301, =ATCC 19262. (NCIMB is the National Collection of Industrial and Marine Bacteria, Ltd., Aberdeen, Scotland; ATCC is the American Type Culture Collection, Rockville, Md.; IAM is the Institute of Applied Microbiology, The University of Tokyo, Tokyo, Japan.)

$b=$ IFO 12985, =NCIMB 302, =ATCC 43555. (IFO is the Institute for Fermentation Osaka, Osaka, Japan.)

$c=$ Strain K-12.

notes the type strain). The type strains of Marinomonas vaga and Marinomonas communis (IAM $12923^{\mathrm{T}}$ and IAM $12914^{\mathrm{T}}$ ) and Escherichia coli IAM 1264 (strain K-12) were used as distantly related reference strains.

Morphological, biochemical, and physiological characterization. Conventional phenotypic characteristics (Table 2) were determined by methods we have described previously $(1,3)$. Alginate hydrolysis activity was determined by both our previously described method (1) and the method that was described by Schlesner et al. (18). In the latter method, the formation of a clear zone was detected by flooding the plate of marine agar 2216 (catalog no. 0979; Difco) containing $1 \%$ sodium alginate with a diluted Lugol solution which produces brown alginate-iodine complex. Simple matching coefficient determination was used to indicate phenotypic similarities on the basis of results of assimilation tests with 145 organic carbon substrates as sole sources of carbon (3). The auxanographic API galleries for 48 carbohydrates (API $50 \mathrm{CH}$ galleries), 49 organic acids (API 50AO galleries), and 49 amino acids and amines (API 50AA galleries) (Laboratoire de Recherche API, La Balme-les-Grottes, MontalleuVercieu, France) were used with the defined basal medium described by Baumann et al. (8). The test with 2-ketogluconate was omitted because precipitate appeared in fresh

TABLE 2. Ubiquinone compositions of the Alteromonas strains used

\begin{tabular}{lcccc}
\hline \multirow{2}{*}{\multicolumn{1}{c}{ Strain }} & \multicolumn{4}{c}{ Ubiquinone composition $^{a}$} \\
\cline { 2 - 5 } & $\mathrm{Q}-7$ & $\mathrm{Q}-8$ & $\mathrm{Q}-9$ & $\mathrm{Q}-10$ \\
\hline A. atlantica IAM $12927^{\mathrm{Tb}}$ & $\mathrm{T}$ & 96 & 2 & \\
A. atlantica $512-\mathrm{M}$ & 1 & 96 & 1 & $\mathrm{t}$ \\
A. atlantica $512-\mathrm{T}$ & $\mathrm{T}$ & 95 & 2 & $\mathrm{t}$ \\
A. atlantica $512-\mathrm{W}$ & $\mathrm{T}$ & 97 & $\mathrm{t}$ & $\mathrm{t}$ \\
A. atlantica $511-\mathrm{T}$ & 1 & 97 & 2 & \\
A. atlantica T9 & $\mathrm{T}$ & 96 & 2 & \\
A. carrageenovora IAM $12662^{\mathrm{Tb}}$ & $\mathrm{T}$ & 97 & 1 & $\mathrm{~T}$ \\
\hline
\end{tabular}

${ }^{a}$ Composition expressed as percent total ubiquinone. $\mathrm{T}$, between 0.5 and $1.0 \%$; $t$, less than $0.5 \%$.

${ }^{b}$ Data from reference 2 . medium without inoculum. Positive results were recorded when better growth than what was without any carbon compound was obtained.

Determination of moles percent $G+C$ content and DNADNA hybridization. Methods for isolation and purification of DNA were described previously (1). Moles percent $\mathrm{G}+\mathrm{C}$ contents of DNA were determined by the high-performance liquid chromatography (HPLC) method (20). DNA-DNA hybridization experiments were performed by the membrane filter method (19). Reference DNAs were labeled with $\left[{ }^{3} \mathrm{H}\right] \mathrm{dCTP}$ by nick translation (15) by using a nick translation kit (Takara Shuzou Co., Ltd., Kyoto, Japan). The reassociation mixture consisted of $10 \mu \mathrm{g}$ of unlabeled single-stranded DNA immobilized on a nitrocellulose membrane (type TM-3; pore size, $0.3 \mu \mathrm{m}$; Toyo Roshi Kaisha, Ltd., Tokyo, Japan) and $0.1 \mu \mathrm{g}$ of labeled reference DNA suspended in $0.1 \%$ sodium dodecyl sulfate- $2 \times \mathrm{SSC}(0.3 \mathrm{M} \mathrm{NaCl}$ plus 0.03 $\mathrm{M}$ trisodium citrate). After incubation for $40 \mathrm{~h}$ at $62^{\circ} \mathrm{C}$, the filters were washed and dried according to the method described by Suzuki et al. (19). The radioactivity of the filter was measured with a model LS 7000 liquid scintillation counter (Beckman Instruments, Inc., Fullerton, Calif.). Quantification of DNAs was based on hyperchromicity as described by Johnson (11).

Respiratory quinone analysis. Quinones were extracted from lyophilized cells harvested at early stationary growth phase with chloroform-methanol (2:1) and were purified by thin-layer chromatography on a silica gel with benzene as a developing solvent. The molecular species of quinone was determined from its $R_{f}$ value, and HPLC was employed to analyze the composition of isoprenologs $(1,2)$. Ubiquinone is abbreviated as $Q$, and the number of the side-chain isoprenoid units is shown by the number after the hyphen.

\section{RESULTS}

Five newly isolated strains, " $P$. atlantica" IAM 12927 , and " $P$. carrageenovora" IAM 12662 were polarly flagellated, gram-negative, nonfermentative rods (Fig. 1). No peritrichous cells were observed when the strains were cultivated on solidified media. Their $\mathrm{G}+\mathrm{C}$ contents were 

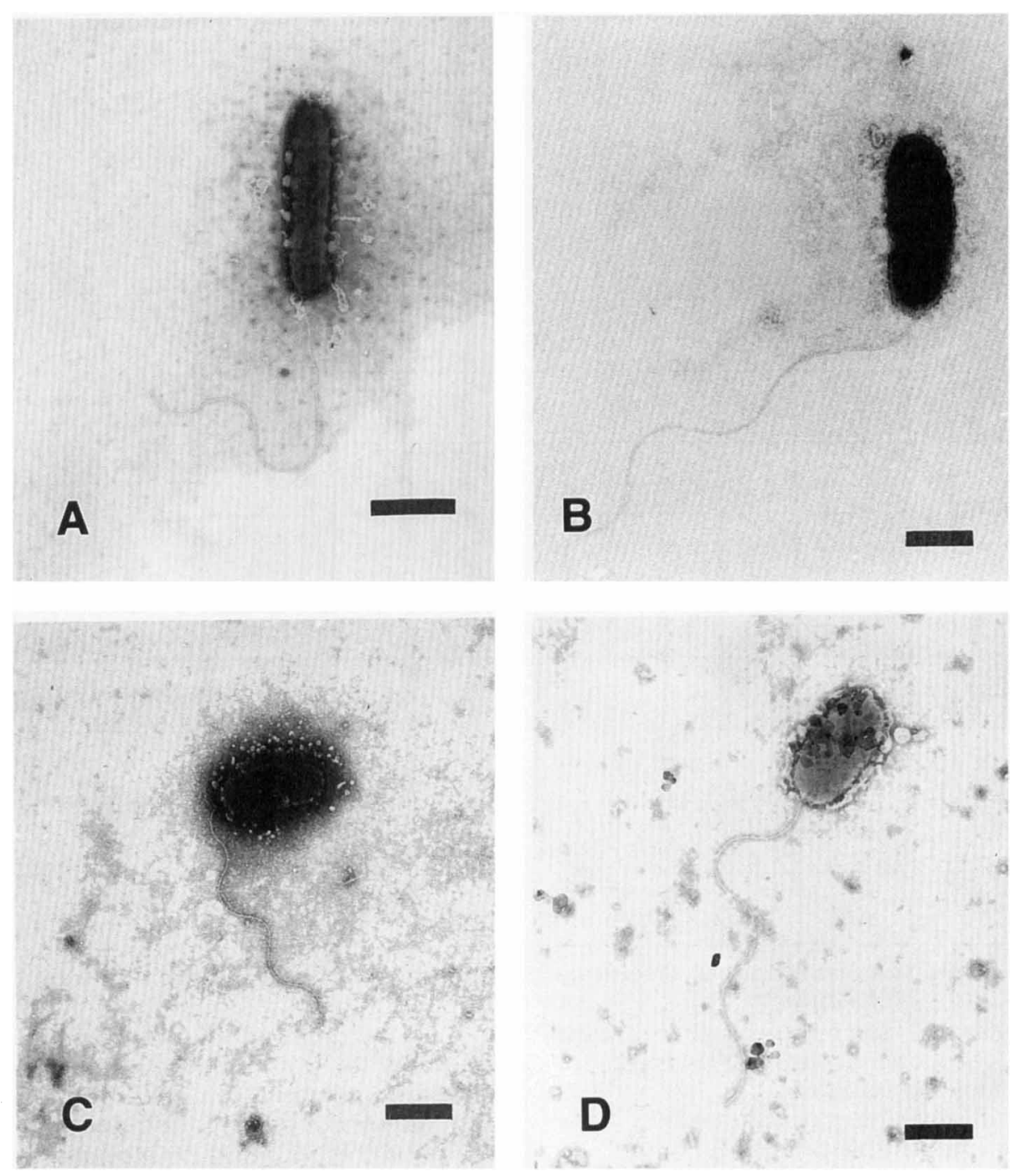

FIG. 1. Electron micrographs of the negatively stained cells of $A$. atlantica and $A$. carrageenovora demonstrating their polar flagellation. (A) $A$. atlantica IAM $12927^{\mathrm{T}}$. (B) $A$. atlantica $512-\mathrm{M}$ (IAM 14161). (C) $A$. atlantica T9 (IAM 14165). (D) $A$. carrageenovora IAM $12662^{\mathrm{T}}$. Bars represent $1 \mu \mathrm{m}$.

39.5 to $41.7 \mathrm{~mol} \%$ (Table 1), suggesting that they should be assigned to the genus Alteromonas (8). Their major ubiquinone was Q-8 (at least $95 \%$ of the total, Table 2), accompanied with small amounts of Q-9, Q-7, and Q-10. The profile is essentially the same as that of Alteromonas species (2).

DNA-DNA hybridization results (Table 1) showed that the five newly isolated strains were closely related to " $P$. atlantica" IAM 12927, with homology values from 82 to $100 \%$. Phenotypically, 79 to $96 \%$ similarity resulted from 145 carbon substrate assimilation tests among these six closely related strains as shown in Fig. 2. They were classified as belonging in a single species. Differential biochemical and physiological features and the carbon source assimilation profiles are shown in Table 3. All strains tested were positive for the following features: acid production from glucose; growth at $\mathrm{pH} 5.5$ and $8.5 ; \mathrm{Na}^{+}$requirement; hydrolyses of esculin, Tween 80, gelatin, casein, and DNA; tyrosine decomposition; phosphatase; $\mathrm{H}_{2} \mathrm{~S}$ production; growth in the presence of vibriostatic agent $\mathrm{O} / 129$ (2,4-diamino-6,7-diisopropylpteridine, $150 \mu \mathrm{g}$ per disk); oxidase; catalase; methylene blue reduction; and assimilation of acetate, propio- nate, pelargonate, caprate, oxalate, glucose, esculin, maltose, starch, and L-glutamate. All strains tested were negative for the following features: growth at $\mathrm{pH} 5.0$; denitrification; production of fluorescein, pyocyanin, and prodigiosin; xanthine decomposition; indole formation; 3-ketolactose production from lactose; growth with $0.4 \%$ phenethyl alcohol; tryptophan deaminase; phenylalanine deaminase; methyl red test; and assimilation of malonate, glutarate, DL-glycerate, L-tartrate, citraconate, itaconate, adipate, pimerate, suberate, azerate, sebacate, glycolate, D-tartrate, meso-tartrate, phenylacetate, benzoate, $m$-hydroxybenzoate, D-mandelate, L-mandelate, phthalate, isophthalate, tert-phthalate, glycine, D- $\alpha$-alanine, L- $\alpha$-alanine, L-leucine, L-isoleucine, L-norleucine, L-valine, DL-norvaline, DL-2-aminobutyrate, L-serine, L-threonine, L-cysteine, L-methionine, L-histidine, D-tryptophan, L-tryptophan, trigonelline, L-aspartate, L-citrulline, DL-kynurenine, L-proline, betaine, creatine, $\beta$-alanine, DL-3-aminobutyrate, DL-4-aminobutyrate, DL-5-aminovalerate, 2-amino-benzoate, 3-aminobenzoate, 4-aminobenzoate, urea, acetamide, sarcosine, ethylamine, butylamine, amylamine, ethanolamine, 1,4-di- 


\begin{tabular}{|c|c|c|c|c|c|c|c|c|c|c|c|c|}
\hline A. atlantica IAM $12927^{\mathrm{T}}$ & & & & & & & & & & & & \\
\hline A. atlantica $512-\mathrm{M}$ & 81 & & & & & & & & & & & \\
\hline A. atlantica 512-T & 89 & 87 & & & & & & & & & & \\
\hline A. atlantica 512-W & 87 & 87 & 96 & & & & & & & & & \\
\hline A. atlantica 511-T & 79 & 83 & 89 & 89 & & & & & & & & \\
\hline A. atlantica T9 & 87 & 83 & 89 & 89 & 89 & & & & & & & \\
\hline A. espejiana IAM $12640^{\mathrm{T}}$ & 83 & 79 & 89 & 89 & 89 & 85 & & & & & & \\
\hline A. carrageenovora IAM $12662^{\mathrm{T}}$ & 81 & 66 & 72 & 74 & 64 & 72 & 68 & & & & & \\
\hline A. haloplanktis IAM $12915^{\mathrm{T}}$ & 64 & 64 & 70 & 70 & 66 & 66 & 74 & 64 & & & & \\
\hline A. undina IAM $12922^{\circ}$ & 60 & 60 & 62 & 58 & 58 & 60 & 62 & 53 & 74 & & & \\
\hline A. tetraodonis IAM $14160^{\circ}$ & 55 & 55 & 64 & 60 & 60 & 53 & 64 & 51 & 79 & 83 & & \\
\hline A. nigrifaciens IAM $13010^{\top}$ & 66 & 58 & 72 & 72 & 72 & 64 & 75 & 60 & 72 & 57 & 66 & \\
\hline A. macleodii IAM $12920^{\mathrm{T}}$ & 47 & 43 & 57 & 57 & 57 & 53 & 60 & 43 & 42 & 45 & 43 & 51 \\
\hline
\end{tabular}

FIG. 2. Similarity coefficients (in percents) among Alteromonas strains, based on the results of assimilation of 145 carbon compounds.

aminobutane, benzylamine, spermine, histamine, tryptamine, D-arabinose, L-xylose, $\beta$-methyl-D-xyloside, sorbose, erythritol, adonitol, inositol, sorbitol, xylitol, dulcitol, $\alpha$-methyl-D-mannoside, inulin, D-lyxose, D-tagatose, D-fucose, L-fucose, D-arabitol, and L-arabitol.

A. espejiana IAM $12640^{\mathrm{T}}$ proved to have values of phenotypic similarity to the six strains ( 79 to $89 \%$ ) nearly the same as those among the six strains, though its DNA homology values were distinctly lower (39 to 55\%). However, the former six strains are clearly distinguished from $A$. espejiana by the following tests: agar hydrolysis, the citrate utilization test, and assimilation of D-xylose and D-mannose as shown in Table 2. They are also phenotypically differentiated from other known nonpigmented Alteromonas species.

\section{DISCUSSION}

On the basis of the above-mentioned phenotypic and genotypic distinctness, we propose $A$. atlantica sp. nov. to be the classification for the six agar-decomposing strains, including "Pseudomonas atlantica" IAM 12927. A. atlantica should be considered to be a member of $A$. haloplanktis rRNA branch because of its significant DNA homology with $A$. espejiana, which was classified on this branch (22). " $P$. atlantica" was originally described by Humm (10) in 1946. Humm isolated and characterized two strains from Atlantic coastal areas, but both have been lost. $A$. atlantica IAM 12927 was isolated and partially characterized as " $P$. atlantica"' by Yaphe in 1955 (28) and has been sometimes referred to as the type strain. We propose strain IAM 12927 be the type strain of $A$. atlantica.
The distinctness of " $P$. carrageenovora" IAM 12662 was shown by the hybridization experiments (Table 1) and the relatively low phenotypic similarity (below $81 \%$; Fig. 2) to any of the tested strains. The highest DNA homology value, $45 \%$, was obtained when the DNA was hybridized with that of $A$. espejiana. This indicates no more than a generic relationship to $A$. espejiana, which can be distinguished by means of tests for starch hydrolysis, agar hydrolysis, citrate utilization, and assimilation of $\mathrm{L}$-malate and aconitate (Table 2). We propose Alteromonas carrageenovora as the name for this enzymologically important, carrageenan-decomposing strain, IAM 12662 (type strain). Differential characteristics of other nonpigmented Alteromonas species are presented in Table 2.

Description of $A$. atlantica sp. nov. A. atlantica (at.lan'. ti.ca. Gr.adj. atlantica, of the Atlantic [Ocean]). Gram-negative, strictly aerobic, polarly flagellated bacterium isolated from seaweeds. Cells are rod shaped, with rounded ends, and are 0.5 to $0.8 \mu \mathrm{m}$ in diameter and 1.5 to $2.3 \mu \mathrm{m}$ long when the organism is grown on marine agar 2216 medium (catalog no. 0979; Difco); the cells occur singly or in pairs. No endospores or capsules are formed. Peritrichous flagellation is not observed when the organism is cultivated on solidified media. Colonies on marine agar 2216 medium are beige to pale yellow orange, are smooth and convex with entire edge, and grow to a diameter of 7.0 to $10.0 \mathrm{~mm}$ in 5 days at $25^{\circ} \mathrm{C}$. The colonies on agar media were strongly depressed by agarase activity. Sodium ion is essential for growth. Are mesophilic and neutrophilic chemoorganotrophs which grow at temperatures between 5 and $35^{\circ} \mathrm{C}$ and at pHs between 5.5 and 8.5. They never grow at $40^{\circ} \mathrm{C}$ and $\mathrm{pH}$ 
TABLE 3. Differential phenotypic features of tested Alteromonas strains

\begin{tabular}{|c|c|c|c|c|c|c|c|c|c|}
\hline \multirow[b]{2}{*}{ Feature } & \multicolumn{9}{|c|}{ Result for strain: } \\
\hline & $\begin{array}{l}\text { A. atlanti- } \\
\mathrm{ca}^{\alpha}\end{array}$ & $\begin{array}{l}\text { A. atlantica } \\
\text { IAM } 12927^{\mathrm{T}}\end{array}$ & $\begin{array}{l}\text { A. carra- } \\
\text { geenovora } \\
\text { IAM } 12662^{\mathrm{T}}\end{array}$ & $\begin{array}{l}\text { A. espejiana } \\
\text { IAM } 12640^{T}\end{array}$ & $\begin{array}{l}\text { A. halo- } \\
\text { planktis } \\
\text { IAM } 12915^{\mathrm{T}}\end{array}$ & $\begin{array}{l}\text { A. undina } \\
\text { IAM } \\
12922^{\mathrm{T}}\end{array}$ & $\begin{array}{c}\text { A. nigri- } \\
\text { faciens IAM } \\
13010^{\mathrm{T}}\end{array}$ & $\begin{array}{l}\text { A. macleo- } \\
\text { dii IAM } \\
12920^{\mathrm{T}}\end{array}$ & $\begin{array}{l}\text { A. tetra- } \\
\text { odonis IAM } \\
14160^{\mathrm{T}}\end{array}$ \\
\hline Acid from mannitol & 100 & + & + & + & - & - & + & + & - \\
\hline \multicolumn{10}{|l|}{ Growth at: } \\
\hline $5^{\circ} \mathrm{C}$ & 100 & + & + & + & + & + & + & - & + \\
\hline $35^{\circ} \mathrm{C}$ & 100 & + & + & + & + & + & - & + & + \\
\hline $40^{\circ} \mathrm{C}$ & 0 & - & - & - & - & - & - & + & - \\
\hline pH 9.0 & 83 & - & + & + & + & + & + & + & + \\
\hline Nitrate reduction & 17 & - & - & - & - & - & - & - & - \\
\hline Melaninlike dark pigment & 33 & - & + & - & + & - & + & - & - \\
\hline ONPG test & 100 & + & + & + & - & - & + & + & - \\
\hline \multicolumn{10}{|l|}{ Hydrolysis of: } \\
\hline Starch & 100 & + & - & + & - & + & + & + & - \\
\hline Alginate & 100 & + & + & + & - & + & + & + & - \\
\hline Agar & 100 & + & - & - & - & - & - & - & - \\
\hline Carrageenan & 83 & - & + & & & & & & \\
\hline Urease & 17 & - & + & + & + & - & + & - & - \\
\hline 2-Ketogluconate from gluconate & 0 & - & - & - & - & - & + & + & - \\
\hline Litmus milk coagulation & 100 & + & + & + & - & + & + & + & + \\
\hline Citrate utilization & 0 & - & + & + & + & + & + & + & + \\
\hline Levan production & 67 & - & + & - & - & - & + & + & - \\
\hline Arginine hydrolysis & 75 & - & + & - & & - & - & & \\
\hline \multicolumn{10}{|l|}{ Assimilation of: } \\
\hline Butyrate & 67 & - & - & + & + & - & + & + & + \\
\hline Isobutyrate & 83 & - & - & + & + & + & + & + & + \\
\hline$n$-Valerate & 83 & - & - & + & + & + & + & + & + \\
\hline Isovalerate & 83 & - & - & + & + & + & - & + & + \\
\hline$n$-Caproate & 17 & - & - & + & + & - & + & - & + \\
\hline Heptanoate & 50 & - & - & + & + & - & + & + & - \\
\hline Caprylate & 33 & - & + & - & - & - & - & + & - \\
\hline Succinate & 67 & + & + & + & + & + & + & + & + \\
\hline Maleate & 0 & - & - & - & - & - & - & + & - \\
\hline Fumarate & 50 & + & + & + & + & - & + & + & + \\
\hline DL-Lactate & 0 & - & - & - & - & - & + & + & - \\
\hline DL-3-Hydroxybutyrate & 17 & - & - & + & - & + & + & + & + \\
\hline D-Malate & 0 & - & - & - & - & - & - & - & + \\
\hline L-Malate & 0 & - & + & - & + & + & + & - & + \\
\hline Levulinate & 0 & - & - & - & - & - & - & + & - \\
\hline 2-Ketoglutarate & 0 & - & + & - & - & - & - & - & - \\
\hline Mesaconate & 17 & - & - & - & - & - & - & - & - \\
\hline Aconitate & 100 & + & - & + & - & - & - & - & - \\
\hline Citrate & 100 & + & + & + & - & - & + & - & - \\
\hline$o$-Hydroxybenzoate & 33 & - & + & - & - & - & - & - & - \\
\hline$p$-Hydroxybenzoate & 0 & - & + & - & - & - & - & - & - \\
\hline L-Phenylalanine & 0 & - & - & - & - & - & - & + & - \\
\hline L-Tyrosine & 17 & - & - & - & - & - & - & - & - \\
\hline L-Ornithine & 0 & - & - & - & - & - & - & + & - \\
\hline L-Lysine & 0 & - & - & - & - & - & + & - & + \\
\hline L-Arginine & 50 & - & - & - & - & - & + & + & + \\
\hline D-Glucosamine & 0 & - & - & - & - & + & - & + & + \\
\hline Glycerol & 83 & + & + & + & - & - & + & + & - \\
\hline L-Arabinose & 0 & - & - & - & - & + & - & - & - \\
\hline D-Ribose & 0 & - & - & - & - & - & - & + & - \\
\hline D-Xylose & 0 & - & - & + & - & - & - & + & - \\
\hline Galactose & 100 & + & + & + & - & - & + & + & - \\
\hline Fructose & 100 & + & + & + & + & - & + & + & - \\
\hline D-Mannose & 100 & + & - & - & - & - & - & - & - \\
\hline Rhamnose & 0 & - & - & - & - & - & - & + & - \\
\hline Mannitol & 100 & + & + & + & - & - & + & + & - \\
\hline$\alpha$-Methyl-D-glucoside & 0 & - & - & - & - & - & - & + & - \\
\hline$N$-Acetyl-D-glucosamine & 0 & - & - & - & - & + & - & + & + \\
\hline Amygdalin & 100 & + & + & + & - & - & - & + & - \\
\hline Arbutin & 0 & - & - & - & - & - & - & + & - \\
\hline Salicin & 0 & - & - & - & - & - & - & + & - \\
\hline Cellobiose & 100 & + & + & + & + & - & - & + & - \\
\hline Lactose & 100 & + & + & + & - & - & + & + & - \\
\hline Melibiose & 100 & + & + & + & - & - & + & + & - \\
\hline
\end{tabular}


TABLE 3-Continued

\begin{tabular}{|c|c|c|c|c|c|c|c|c|c|}
\hline \multirow[b]{2}{*}{ Feature } & \multicolumn{9}{|c|}{ Result for strain: } \\
\hline & $\begin{array}{l}\text { A. atlanti- } \\
c a^{a}\end{array}$ & $\begin{array}{l}\text { A. atlantica } \\
\text { IAM } 12927^{\mathrm{r}}\end{array}$ & $\begin{array}{l}\text { A. carra- } \\
\text { geenovora } \\
\text { IAM } 12662^{\mathrm{T}}\end{array}$ & $\begin{array}{l}\text { A. espejiana } \\
\text { LAM } 12640^{\mathrm{T}}\end{array}$ & $\begin{array}{l}\text { A. halo- } \\
\text { planktis } \\
\text { IAM } 12915^{\mathrm{T}}\end{array}$ & $\begin{array}{l}\text { A. undina } \\
\text { IAM } \\
12922^{\mathrm{r}}\end{array}$ & $\begin{array}{c}\text { A. nigri- } \\
\text { faciens IAM } \\
13010^{\mathrm{T}}\end{array}$ & $\begin{array}{l}\text { A. macleo- } \\
\text { dii IAM } \\
12920^{\mathrm{T}}\end{array}$ & $\begin{array}{l}\text { A. tetra- } \\
\text { odonis IAM } \\
14160^{\mathrm{T}}\end{array}$ \\
\hline Sucrose & 100 & + & + & + & - & + & - & + & + \\
\hline Trehalose & 100 & + & - & + & - & + & - & + & + \\
\hline Melezitose & 0 & - & - & - & - & + & - & + & - \\
\hline Raffinose & 0 & - & + & - & - & - & - & + & - \\
\hline Glycogen & 100 & + & - & + & - & + & + & + & - \\
\hline Gentiobiose & 100 & + & + & + & + & + & - & + & + \\
\hline D-Turanose & 0 & - & - & - & - & - & - & + & - \\
\hline Gluconate & 0 & - & - & - & - & - & + & + & - \\
\hline 5-Ketogluconate & 17 & - & - & - & - & - & - & - & - \\
\hline
\end{tabular}

${ }^{a}$ Percent positive strains. For all tests except arginine hydrolysis, $n=6$; for arginine hydrolysis, $n=4$.

5.0. All strains except IAM $12927^{\mathrm{T}}$ grow at $\mathrm{pH}$ 9.0. Acid is produced from glucose and mannitol. Are positive for hydrolyses of esculin, Tween 80 , gelatin, casein, starch, DNA, alginate, and agar. Chitinase is not produced. Are positive for oxidase and catalase; in the $o$-nitrophenyl- $\beta$-D-galactopyranoside (ONPG) test; and for tyrosine decomposition, phosphatase, $\mathrm{H}_{2} \mathrm{~S}$ production, litmus milk coagulation, and methylene blue reduction. Are negative for nitrate reduction, denitrification, cell pigmentation, amidase, xanthine decomposition, indole production, 2-ketogluconate production from gluconate, 3-ketolactose production from lactose, citrate utilization, $\mathrm{O} / 129$ sensitivity, growth on medium containing $0.4 \%$ phenethyl alcohol, and deaminases for tryptophan and phenylalanine; are negative in the methyl red test; and are negative for curdlanlike polysaccharide production. Some strains produce carrageenase, urease, acetylmethylcarbinol, and melaninlike dark pigment on tyrosinecontaining medium. Luminescence is never observed. Acetate, propionate, butyrate, isobutyrate, $n$-valerate, isovalerate, pelargonate, caprate, oxalate, succinate, aconitate, citrate, glycerol, galactose, glucose, fructose, D-mannose, mannitol, amygdalin, esculin, cellobiose, maltose, lactose, melibiose, sucrose, trehalose, starch, glycogen, gentiobiose, and L-glutamate are utilized by $67 \%$ or more of the strains as sole sources of carbon and energy. The following compounds are not utilized by at least $67 \%$ of the strains: $n$-caproate, caprylate, malonate, maleate, glutarate, adipate, pimerate, suberate, azerate, sebacate, glycolate, DL-lactate, DL-glycerate, DL-3-hydroxybutyrate, D-malate, L-malate, D-tartrate, L-tartrate, meso-tartrate, levulinate, 2-ketoglutarate, citraconate, itaconate, mesaconate, phenylacetate, benzoate, $o$-hydroxybenzoate, $m$-hydroxybenzoate, $p$-hydroxybenzoate, D-mandelate, L-mandelate, phthalate, isophthalate, tert-phthalate, glycine, D- $\alpha$-alanine, L- $\alpha$-alanine, L-leucine, L-isoleucine, L-norleucine, L-valine, DL-norvaline, DL-2-aminobutyrate, L-serine, L-threonine, L-cysteine, L-methionine, L-phenylalanine, L-tyrosine, L-histidine, D-tryptophan, L-tryptophan, trigonelline, L-aspartate, L-glutamate, L-ornithine, L-lysine, L-citrulline, DL-kynurenine, L-proline, betaine, creatine, $\beta$-alanine, DL-3-aminobutyate, DL-4-aminobutyrate, DL-5-aminovarelate, 2-aminobenzoate, 3-aminobenzoate, 4-aminobenzoate, urea, acetoamide, sarcosine, ethylamine, butylamine, amylamine, ethanolamine, benzylamine, 1,4-diaminobutane, spermine, histamine, tryptamine, D-glucosamine, erythritol, D-arabinose, L-arabinose, D-ribose, D-xylose, L-xylose, adonitol, $\beta$-methyl-D-xyloside, sorbose, rhamnose, dulcitol, inositol, sorbitol, $\alpha$-methyl-Dmannoside, $\alpha$-methyl-D-glucoside, $N$-acetyl-D-glucosamine, arbutin, salicine, inulin, melezitose, raffinose, xylitol, D-turanose, D-lyxose, D-tagatose, D-fucose, L-fucose, D-arabitol, L-arabitol, gluconate, and 5-ketogluconate. The $\mathrm{G}+\mathrm{C}$ content of the DNA ranges from 40.6 to $41.7 \mathrm{~mol} \%$. Isoprenoid quinone is Q-8. Strains have been isolated from marine macroalgae collected from both the Atlantic and Pacific coastal areas. The type strain is IAM 12927 (=NCIMB 301, =ATCC 19262). Strains 512-M, 512-T, 512-W, 511-T, and T9 were deposited to the Institute of Applied Microbiology culture collection as IAM 14161, IAM 14162, IAM 14163, IAM 14164, and IAM 14165, respectively.

Description of $A$. carrageenovora sp. nov. A. carrageenovora (car.ra.gee.no'.vo.ra. M.L.n. carrageenum, carrageen, another name for carrageenan; L.v. voro, to devour; M.L.fem.adj. carrageenovora, carrageenan decomposing). Gram-negative, strictly aerobic, polarly flagellated bacterium isolated from seaweeds. Cells are rod shaped, with rounded ends, and are 0.7 to $0.8 \mu \mathrm{m}$ in diameter and 1.9 to $2.5 \mu \mathrm{m}$ long when the organism is grown on marine agar 2216 medium (catalog no. 0979; Difco); the cells occur singly or in pairs. No endospores or capsules are formed. Peritrichous flagellation is not observed when the organism is cultivated on solidified media. Colonies on marine agar 2216 medium are beige to pale yellow orange, circular, and smooth and convex with entire edge and grow to a diameter of 6.0 to 8.0 $\mathrm{mm}$ in 5 days at $25^{\circ} \mathrm{C}$. Sodium ion is essential for growth. Are mesophilic and neutrophilic chemoorganotrophs which grow at temperatures between 5 and $35^{\circ} \mathrm{C}$ and at pHs between 5.5 and 9.0. No growth occurs at $40^{\circ} \mathrm{C}$ and $\mathrm{pH} \mathrm{5.0.} \mathrm{Acid} \mathrm{is}$ produced from glucose and mannitol. Are positive for hydrolyses of esculin, Tween 80 , gelatin, casein, DNA, alginate, and carrageenan. Chitin, starch, and agar are not hydrolyzed. Are positive for oxidase and catalase; in the ONPG test; and for tyrosine decomposition, phosphatase, urease, arginine hydrolysis, citrate utilization, $\mathrm{H}_{2} \mathrm{~S}$ production, litmus milk coagulation, and methylene blue reduction. Are negative for nitrate reduction, denitrification, cell pigmentation, amidase production, xanthine decomposition, indole production, 2-ketogluconate production from gluconate, 3-ketolactose production from lactose, $\mathrm{O} / 129$ sensitivity, growth on medium containing $0.4 \%$ phenethyl alcohol, and deaminases for tryptophan and phenylalanine; are negative in the methyl red test; and are negative for curdlanlike polysaccharide production. Melaninlike diffusible dark pigment was produced on tyrosine-containing medium. Luminescence was never observed. Acetate, propionate, $n$-valerate, caprylate, pelargonate, caprate, oxalate, succi- 
nate, fumarate, L-malate, 2-ketoglutarate, citrate, $o$-hydroxybenzoate, $p$-hydroxybenzoate, L-glutamate, glycerol, galactose, glucose, fructose, mannitol, amygdalin, esculin, cellobiose, maltose, lactose, melibiose, sucrose, raffinose, starch, and gentiobiose are utilized as sole sources of carbon and energy. The following compounds are not utilized: butyrate, isobutyrate, isovalerate, $n$-caproate, heptanoate, malonate, maleate, glutarate, adipate, pimerate, suberate, azerate, sebacate, glycolate, DL-lactate, DL-glycerate, DL-3hydroxybutyrate, D-malate, D-tartrate, L-tartrate, meso-tartrate, levulinate, citraconate, itaconate, mesaconate, aconitate, phenylacetate, benzoate, $m$-hydroxybenzoate, D-mandelate, L-mandelate, phthalate, isophthalate, tert-phthalate, glycine, D- $\alpha$-alanine, L- $\alpha$-alanine, L-leucine, L-isoleucine, L-norleucine, L-valine, DL-norvaline, DL-2-aminobutyrate, L-serine, L-threonine, L-cysteine, L-methionine, L-phenylalanine, L-tyrosine, L-histidine, D-tryptophan, L-tryptophan, trigonelline, L-aspartate, L-ornithine, L-lysine, L-citrulline, L-arginine, DL-kynurenine, L-proline, betaine, creatine, $\beta$-alanine, DL-3-aminobutyate, DL-4-aminobutyrate, DL-5-aminovarelate, 2-aminobenzoate, 3-aminobenzoate, 4-aminobenzoate, urea, acetoamide, sarcosine, ethylamine, butylamine, amylamine, ethanolamine, benzylamine, 1,4-diaminobutane, spermine, histamine, tryptamine, D-glucosamine, erythritol, D-arabinose, L-arabinose, D-ribose, D-xylose, L-xylose, adonitol, $\beta$-methyl-D-xyloside, D-mannose, sorbose, rhamnose, dulcitol, inositol, sorbitol, $\alpha$-methyl-D-mannoside, $\alpha$ methyl-D-glucoside, $N$-acetyl-D-glucosamine, arbutin, salicine, trehalose, inulin, melezitose, glycogen, xylitol, D-turanose, D-lyxose, D-tagatose, D-fucose, L-fucose, D-arabitol, L-arabitol, gluconate, and 5-ketogluconate. The $\mathrm{G}+\mathrm{C}$ content of the DNA is $39.5 \mathrm{~mol} \%$. Isoprenoid quinone is Q-8. The type strain is IAM 12662 (=IFO 12985, =NCIMB 302, =ATCC 43555).

\section{ACKNOWLEDGMENTS}

We thank Aiko Hirata (Institute of Applied Microbiology, The University of Tokyo) and Mitsuru Yokoyama (University of Occupational and Environmental Health) for their technical advice on electron microscopy.

\section{REFERENCES}

1. Akagawa, M., and K. Yamasato. 1989. Synonymy of Alcaligenes aquamarinus, Alcaligenes faecalis subsp. homari, and Deleya aesta: Deleya aquamarina comb. nov. as the type species of the genus Deleya. Int. J. Syst. Bacteriol. 39:462-466.

2. Akagawa-Matsushita, M., T. Itoh, Y. Katayama, H. Kuraishi, and $K$. Yamasato. Isoprenoid quinone composition of some marine Alteromonas, Marinomonas, Deleya, Pseudomonas and Shewanella species. J. Gen. Microbiol., in press.

3. Akagawa-Matsushita, M., Y. Yamada, and K. Yamasato. 1991. Characterization and identification of a restriction enzyme producing marine bacterium Deleya marina IAM 14114. Bull. JFCC 7:28-32.

4. Ando, Y., and K. Inoue. 1961. Decomposition of alginic acid by microorganisms. IV. On the Vibrio-type bacteria, newly isolated from the decaying Laminaria. Bull. Jpn. Soc. Sci. Fish. 27:339-341.

5. Andrykovitch, G., and I. Marx. 1988. Isolation of a new polysaccharide-digesting bacterium from a salt marsh. Appl. Environ. Microbiol. 54:1061-1062.

6. Aoki, T., T. Araki, and M. Kitamikado. 1990. Isolation and purification of a porphyran-degrading bacterium. Bull. Jpn. Soc. Sci. Fish. 56:819-823.

7. Aoki, T., T. Araki, and M. Kitamikado. 1990. Purification and characterization of $\beta$-agarase from Vibrio sp. AP-2. Bull. Jpn. Soc. Sci. Fish. 56:825-830.
8. Baumann, L., P. Baumann, M. Mandel, and R. D. Allen. 1972. Taxonomy of aerobic marine eubacteria. J. Bacteriol. 110:402-429.

9. De Vos, P., A. Van Landschoot, P. Segers, R. Tytgat, M. Gillis, M. Bauwens, R. Rossau, M. Goor, B. Pot, K. Kersters, P. Lizzaraga, and J. De Ley. 1989. Genotypic relationships and taxonomic localization of unclassified Pseudomonas and Pseudomonas-like strains by deoxyribonucleic acid:ribosomal ribonucleic acid hybridizations. Int. J. Syst. Bacteriol. 39:35-49.

10. Humm, H. J. 1946. Marine agar-digesting bacteria of the south Atlantic coast. Bull. Duke Univ. Mar. Lab. 3:43-75.

11. Johnson, J. L. 1991. DNA reassociation experiments, p. 21-44. In E. Stackebrandt and M. Goodfellow (ed.), Nucleic acid techniques in bacterial systematics. John Wiley \& Sons, New York.

12. Johnston, K. H., and E. L. McCandless. 1973. Enzymic hydrolysis of the potassium chloride soluble fraction of carrageenan: properties of " $\mathrm{k}$-carrageenases" from Pseudomonas carrageenovora. Can. J. Microbiol. 19:779-788.

13. Kinoshita, S., Y. Kumoi, A. Ohshima, T. Yoshida, and N. Kasai. 1991. Isolation of an alginate-degrading organism and purification of its alginate lyase. J. Ferment. Bioeng. 72:74-78.

14. McLean, M. W., and F. B. Williamson. 1979. k-Carrageenase from Pseudomonas carrageenovora. Eur. J. Biochem. 93:553-558.

15. Rigby, P. W. J., M. Diekmann, C. Rhodes, and P. Berg. 1977. Labelling deoxyribonucleic acid to high specific activity in vitro by nick translation with DNA polymerase 1. J. Mol. Biol. 113:237-251.

16. Sarwar, G., T. Sakata, and D. Kakimoto. 1983. Isolation and characterization of carrageenan-decomposing bacteria from marine environment. J. Gen. Appl. Microbiol. 29:145-155.

17. Sawabe, T., Y. Ezura, and T. Kimura. 1992. Characterization of an alginolytic marine bacterium from decaying rishiri-kombu Laminaria japonica. Bull. Jpn. Soc. Sci. Fish. 58:141-145.

18. Schlesner, H., C. Bartels, M. Sittig, M. Dorsch, and E. Stackebrandt. 1990. Taxonomic and phylogenetic studies on a new taxon of budding, hyphal Proteobacteria, Hirschia baltica gen. nov., sp. nov. Int. J. Syst. Bacteriol. 40:443-451.

19. Suzuki, K., T. Kaneko, and K. Komagata. 1981. Deoxyribonucleic acid homologies among coryneform bacteria. Int. J. Syst. Bacteriol. 31:131-138.

20. Tamaoka, J., and K. Komagata. 1984. Determination of DNA base composition by reversed-phase high-performance liquid chromatography. FEMS Microbiol. Lett. 25:125-128.

21. Turvey, J. R., and J. Christison. 1967. The hydrolysis of algal galactans by enzymes from a Cytophaga species. Biochem. J. 105:311-316.

22. Van Landschoot, A., and J. De Ley. 1983. Intra- and intergeneric similarities of the rRNA cistrons of Alteromonas, Marinomonas (gen. nov.) and some other Gram-negative bacteria. J. Gen. Microbiol. 129:3057-3074.

23. Wang, X. 1985. A new strain of agar-digesting bacteria which is able to decolorize melanoidin. Acta Microbiol. Sin. 25:289-293. (In Chinese with English summary.)

24. Weigel, J., J. R. Turvey, and W. Yaphe. 1965. The enzymic hydrolysis of k-carrageenan with k-carrageenase from Pseudomonas carrageenovora. Proc. Int. Seaweed Symp. 5:329-332.

25. Weigel, J., and W. Yaphe. 1966. The enzymic hydrolysis of carrageenan by Pseudomonas carrageenovora: purification of a к-carrageenase. Can. J. Microbiol. 12:939-947.

26. Yamaura, I., T. Matsumoto, M. Fumatsu, H. Shigeiri, and T. Shibata. 1991. Purification and some properties of agarase from Pseudomonas sp. PT-5. Agric. Biol. Chem. 55:2531-2536.

27. Yaphe, W. 1957. The use of agarase from Pseudomonas atlantica in the identification of agar in marine algae (Rhodophyceae). Can. J. Microbiol. 3:987-993.

28. Yaphe, W., and B. Baxter. 1955. The enzymic hydrolysis of carrageenin. Appl. Microbiol. 3:380-383.

29. Yaphe, W., and K. Morgan. 1959. Enzymic hydrolysis of fucoidin by Pseudomonas atlantica and Pseudomonas carrageenovora. Nature (London) 183:761-762.

30. Yonemoto, Y., K. Murata, A. Kimura, H. Yamaguchi, and K. Okayama. 1991. Bacterial alginate lyase: characterization of alginate lyase-producing bacteria and purification of the enzyme. J. Ferment. Bioeng. 72:152-157. 